\title{
Mental Imagery, Optimism, and Self-efficacy: The Role of Imagery Perspective and Imagery Modality in Positive Cognition
}

\author{
Claudia A. Pop ${ }^{1} \&$ Alexandru I. Tiba ${ }^{2 *}$ \\ ${ }^{I}$ Department of Clinical Psychology and Psychotherapy, Babes Bolyai-University, Cluj Napoca, Romania. \\ ${ }^{2}$ Department of Psychology, University of Oradea, Romania.
}

Received 18.07.2019; Received revised 25.11.2019; Accepted 10.12.2019

Available online 31.12.2019

\begin{abstract}
This study examined whether using different imagery perspectives and modalities plays a role in the link between vividness of imagining positive events and positive cognition such as optimism, self-efficacy and memory for positive mood. We asked participants to complete self-rating scales of positive cognition and to imagine doing various actions in positive situations from the external and internal perspectives of visual modality and when using kinesthetic modality. We found that vividness of imagining actions in positive situations from an external perspective predicts all positive cognitions: optimism and self-efficacy and memory of positive mood. The vividness of imagining actions in positive situations from the internal perspective of visual modality and kinesthetic imagery predicted only self-efficacy and memory of positive mood but not optimism. We discuss the findings in light of existing theories regarding imagery and positive cognition and suggest several possibilities of using imagery perspective for imagery interventions.
\end{abstract}

Keywords: vividness of imagery, imagery perspective, cognition, optimism, self-efficacy, positive mood.

Address of correspondence: Alexandru I. Tiba, 4, Calea Clujului Street, 410053, Oradea, Bihor, Romania.

E-mail: alexandrutiba@gmail.com.

\section{Introduction}

Expecting more positive things in life than negative (i.e., dispositional optimism) and having high confidence of doing things that are important and coping with future stress (i.e., self-efficacy) have both been evidenced as having a key role in mental health, adaptation and coping with strain and illness (Benight \& Harper, 2002; Carver \& Schreier, 2014; Feng et al., 2015; Folkman et al., 1986; Rasmussen et al., 2009). Given the importance of positive cognitions such as optimism for health and well- being, developing theories of the mechanisms underlying positive cognitions may prove a fruitful avenue for optimizing the existent clinical treatments, and for increasing well-being.

Research showed that optimism and self-efficacy are closely related (Magaletta \& Oliver, 1999). Both selfefficacy and optimism are propositional types of cognition that reflect general beliefs of individuals as stable propositional descriptions of the future and behaviour, rather than the experience of the individual at that particular moment. Investigation of the possible mechanisms underlying optimism showed that vividness of imagery of positive events is a cognitive marker for optimism (Blackwell et al., 2013; Ji et al., 2017). Similarly, imagery has been proposed as an important mechanism for self-efficacy (Bandura, 1997). Although the ability to imagine future positive events has been proposed to play the role of a cognitive mechanism for optimism in both healthy and clinical samples (Blackwell et al., 2013; Ji et al., 2017; Sharot et al., 2007) it is unknown whether this cognitive marker also underlies self-efficacy. Moreover, it is not known whether vividness of imagining the future functions as a general imagery mechanism or if there are distinct mechanisms linked to different imagery modalities (motor or visual imagery) or to different imagery characteristics (imagery perspective) underlying the differences in imagining positive events in relation with optimism and self-efficacy. Understanding how different characteristics of imagery for positive events relate with optimism and self-efficacy may inform imagery-based interventions (Malouff \& Schutte, 2016) and specify conditions in which they may be more or less efficient.

One characteristic of imagery is imagery perspective (Nigro \& Neisser, 1983). Imagery perspective refers to the point from which people imagine a situation such as seen by their eyes (first person perspective or internal visual 
imagery) or as seen by another person (observer perspective or external visual imagery). Consistently, research studies found that imagining situations from an internal perspective (compared to an external perspective) results in different in emotional, cognitive, and clinical outcomes (Nigro \& Neisser, 1983; Wallace-Hadrill \& Kamboj, 2016). For instance, compared to the internal perspective, the external perspective is predominantly used by depressive people when imagining positive events (Williams \& Moulds, 2008), moderates the effects of imagery based interventions (Burnett Heyes et al., 2017), and is related to attenuation in both positive (Holmes et al., 2008; Gruber et al., 2009; Nelis et al., 2013; but see Nelis et al., 2012 for contrary findings) and negative emotions (Kross \& Ayduk, 2008; Grisham et al., 2011; Wisco \& Nolen-Hoeksema, 2011, White et al., 2015; but see results of Hung \& Mukhopadhyay, 2012 and Katzir \& Eyal, 2013). Furthermore, compared to the internal imagery perspective, the external imagery perspective does not impact movement (Stins et al., 2015), but recruits additional neural areas (e.g., lingual gyrus) and processes (image transformation) that are not engaged by the internal perspective (Jackson et al. 2006).

Another important difference found between external and internal imagery perspectives is related to their dissociated effect on cognitive processing. Previous studies showed that requiring participants to use an observer perspective when they imagine different situations favours the adoption of a propositional style of processing while internal perspective induce an experiential style of processing (Libby \& Eibach, 2011a; Libby et al., 2014; Shaeffer et al., 2015). Imagining situations from an external perspective distorts our predictions to reflect individual differences in their general beliefs rather than nearby experiences and associations while adopting internal perspective favors integration of associative information and nearby experiences in our thinking (Libby et al., 2014). According to the "processing style" view of imagery perspective (Libby \& Eibach, 2011b), people who imagine more vividly positive situations from an external perspective would have higher levels of optimism and selfefficacy, which are propositional types of information, but not higher levels of types of cognition based on associative type of information such as remembering past positive mood (e.g., Kaplan et al. 2016).

These findings suggest several hypotheses. Our first hypothesis is that higher levels of vividness of imagining positive situations from an external perspective will correlate with higher levels of dispositional optimism and self-efficacy, but with lower levels of remembered past positive mood.

Since previous studies found an internal perspective to be related with high levels of positive emotions (Holmes et al., 2008), our second hypothesis is that higher levels of vividness of imagining using an internal perspective will be related to higher levels of remembered past positive mood but not with dispositional optimism. Taking into account research that found an increase in self-efficacy after mental rehearsal training using an internal perspective (Buck et al., 2016), and the close link between an internal perspective of imagery and movement (Stins et al., 2015), we predict that higher levels of vividness from an internal perspective will be correlated to higher endorsements of beliefs based on action related information such as selfefficacy.

Previous research showed that when imagining the same situation using different modalities, such as visual and kinesthetic modalities, important differences can be observed. Imagining actions based on visual or kinesthetic task requirements recruits different brain systems (visual vs. motor brain systems, Guillot et al., 2009; Sirigu \& Duhamel, 2001), has different effects on brain corticospinal excitability (Stinear et al., 2006) and behaviour (e.g. postural regulation, Grangeon et al., 2011). Thus, the vividness of imagining actions in kinesthetic modality would rather reflect differences in accessing motor representations and motor system while vividness of imagining actions in visual external modality would reflect differences in accessing visual based representations and visual system. Self-efficacy references beliefs about the confidence of realizing actions (i.e., „I am confident that I could deal efficiently with unexpected events"; Schwarzer \& Jerusalem, 1995) and is presumably based on the availability of action information. Optimism indexes general beliefs about positive future situations with no direct reference for actions presumably not requiring action information but visual representations of future (i.e., "Overall, I expect more good things to happen to me than bad"; Carver \& Scheier, 1994). Thus, the levels of vividness of action imagery when using kinesthetic modality (which is considered to recruit motor information in the thinking process) and not in visual modality would have an effect on self-efficacy rather than on optimism. We hypothesize that higher levels of vividness when imagining actions in positive situations using kinesthetic modality will be correlated with higher levels of self-efficacy but no such relation will be expected for optimism. Based on proposition processing perspective approach, no prediction regarding the vividness of imagining positive situations using kinesthetic imagery and estimations of the level of positive situations was made. Yet, kinestetic imagery can be assimilated to an internal processing style. We also tested whether the relations between imagery perspective and remembered mood are mediated by the level selfefficacy cognitions.

\section{Method}

\section{Participants}

One hundred and ten university students who participated in a larger study on mental imagery (Mental Imagery and Beliefs Study) were selected for this study. Four participants were lost because they did not complete the vividness ratings. Our final sample included 106 participants ( 84 women and 22 men). Participants ranged in age from 18 to 45 years $(\mathrm{M}=21.26, \mathrm{SD}=4.93)$. Participants have received course credits for their participation. The study was conducted in accordance with the Declaration of Helsinki (World Medical Association [WMA], 2013).

\section{Procedure}

After signing the informed consent participants completed a demographic questionnaire and mood and cognitive scales. We administered the questionnaires in groups of 10 to 15 participants. In this study, we selected data only from Generalized Self-efficacy Scale (Schwarzer and Jerusalem 1995), The Life Orientation Test (Scheier et al. 1994), and Profile of Affective Distress Scale (David and Macavei 2007). Data from the other scales (e.g., Patient Health Questionnaire 9; PHQ-9, Kroenke et al. 2001; and simulation scales) administered in this project were included into another study on affective imagery. The participants underwent the imagery task for another 15 
minutes. Visual internal, external and kinesthetic imagery tasks were explained by reference to the example of "writing a number" ("External imagery is seeing you how another person would see you when you write the number; internal imagery is imagining what you see when you write the number and kinesthetic imagery is the feeling of movements in your hand while you write the number"). Participants imagined doing twelve actions in positive, negative and neutral contexts. Each situation was imagined three times: firstly from a visual external perspective, secondly from a visual internal perspective and thirdly, in the kinesthetic modality. After forming each image, participants rated the vividness for the image they formed on a rating scale between 1 (Perfectly clear, as you would have the seeing now) to 5 (No image or sensation, just thinking of that image). At the end, they responded to questions following the procedure used in Vividness of Movement Imagery Questionnaire-Revised (VMIQ-R, Callow and Roberts 2010).

\section{Measures}

Generalized Self-efficacy Scale (GSES, Schwarzer and Jerusalem 1995). GSES is a 10-items self-report questionnaire which measures perceived efficacy in dealing with stress, challenges or novel experiences. People rate items on a 4-point Likert-type scale from 1 (not true at all) to 4 (very true) items such as "If I am in trouble, I can usually think of a solution". In our study, the Cronbach alpha $(\alpha)$ coefficient of GSES was 0.81 . Previously reliability for the Romanian population was established at $\alpha=0.84$ (Jerusalem \& Schwarzer, 2007).

The Life Orientation Test (LOT-R; Scheier, Carver, \& Bridges, 1994) measures self-reported dispositional optimism. Subjects' responses indicate their level of agreement on a five-point Likert scale, ranging from strongly disagree to strongly agree. In the original scoring method, the pessimism items are inversely scored and the filler items are not scored. We computed a general optimism score $(\alpha=.58)$, in line with previous studies that investigated the relationship between optimism and vividness of imagery (e.g., Blackwell et al. 2013). Previously established reliability $(\alpha=.78)$ and test-retest correlation $(\mathrm{r}=.79)$ coefficients were acceptable (Scheier et al., 1994).

Profile of Affective Distress (PDA, Opris \& Macavei, 2007). We measured memory of positive mood by asking participants to read 39 adjective describing emotions (positive and negative emotions) and to rate for each item how much they felt each emotion during the last week on a Likert type scale. Participants had to indicate on a 0 (not at all) to 4 (very much) Likert type scale indicating their emotional experience for the last week. For the present study we calculated the score for a positive subscale containing 10 items of adjectives $(\alpha=.82)$ describing positive emotions (e.g., happy, satisfied, joyful, glad, content, enthusiastic, delighted, feeling well, cheerful, merry). To avoid overlapping items with LOT-R scale, we excluded the item ("I feel optimistic") and items indexing arousal (e.g., feeling dynamic and full of vitality). Previously established reliability for the general test was $\alpha=.94$ indicating good properties of the scale (Opris \& Macavei, 2007).

Prospective Movement Imagery Task. PMIT is an imagery task built for the present study on the structure of the Vividness of Movement Imagery QuestionnaireRevised (VMIQ-R; Callow and Roberts 2010; Roberts et al. 2008). We modified VMIQ items by adding to each movement item positive, negative contexts based on items from Prospective Imagery Task (PIT; Holmes et al. 2008; Morina et al. 2011; Stober 2000). VMIQ-R dissociates between visual, visual-motor and kinesthetic modalities of motor imagery allowing for the study of imagery perspective and visual and kinesthetic modalities. It comprises twelve items describing movements (e.g., "walking, riding a bike"). Participants are asked to imagine each movement from a third -person view, then from a first-person view and then from a kinesthetic view. For the task used in this study, we retained the structure and the items of the VMIQ-R but we added positive, negative and neutral future contexts for actions. Four positive and four negative situations were selected from Prospective Imagery Task (PIT) (Macleod et al., 1996; Stober, 2000). For instance, we added to an action item from VMIQ-R (e.g., Running) a positive item from PIT (e.g., „People will admire you"). The resulting item was Running and people admiring you. We used a similar strategy for building negative items (e.g., „People will find you dull and boring" was added to "Jumping sideways" resulting in "Jumping sideways and people finding you dull and boring"). A nonemotional context was added to balance the complexity of neutral items depicting only action (e.g., to the item "Walking" was added on the street resulting in Walking on the street). Participants had to imagine each item (eyes closed) and then to rate the vividness and difficulty of the image.

\section{Data analyses}

A multivariate regression was computed for each hypothesis to control for multiple dependent variables. Bootstrapping method based on 5,000 resamples was used to test mediation (Preacher \& Hayes, 2008). Levene's test indicates variation inflation factors less than 3 for all variables suggesting the absence of multicollinearity. The visual inspection of the plots of the standardized residuals and standardized predicted value suggests the homoscedasticity condition for each variable. We excluded outliers for each variable based on SPSS outlier analyses to reduce their effect on the relations.

\section{Results}

Table 1 presents demographic data, means and standard deviation for the main variables

Multivariate regression coefficients between vividness of imagery for actions in positive situations, dispositional optimism, self-efficacy and memory of positive mood are described in Table 2.

As seen in Table 2, the multivariate regression equation showed that higher levels of vividness of imagery of positive events from the external perspective of visual modality predict higher levels of positive cognitions.

Thus, significant relations were observed for dispositional optimism $(\beta=-.117, \mathrm{p}=.031)$, self-efficacy $(\beta$ $=-.118, p=.001)$, and memory of positive $\operatorname{mood}(\beta=$ $.145, \mathrm{p}=.016)$. In summary, the regression analysis based on our data supported our hypothesis that higher levels of vividness of imagining positive events from an external visual perspective are related with higher levels of optimism and self-efficacy. Yet, contrary to our hypothesis, higher levels of vividness of imagining positive events from an external visual perspective were also related to higher levels of memory of positive mood. Since memory of positive mood may also reflect positive appraisals of the individuals at the moment of assessing 
vividness of internal perspective and of kinesthetic imagery predicted only the action related positive cognition such as self-efficacy. Although vividly imagining actions in positive situations predicted remembering higher levels of positive mood, this relation is mediated by the level of propositional positive cognitions (self-efficacy) at the moment of remembering positive mood. We found a total mediation of this effect across both visual perspectives and kinesthetic modality.

In other words, people who vividly see themselves in their mind as another person would see them are also more optimistic and more confident they could do important things. Being more confident in their ability to successfully overcome difficulties (due to vividly imagining how they act in positive situations) is likely to induce a positive memory bias making them remember having intense positive mood the previous week. Similarly, people who vividly see in their mind what they would see if they did those positive actions are more confident that they can do important things and cope with stress (but they are not more optimistic). Being more confident in successfully overcoming difficulties at the time of remembering previous positive mood seems to account for the fact that people who vividly imagine actions in positive situations also remember more positive mood across both imagery perspectives and modalities. These findings partially support our first hypothesis about the effect of imagery perspective on the style of processing. We expected that higher VEPOS will be associated with higher levels of positive beliefs (optimism and self-efficacy) and lower levels of estimations of past positive mood. In turn, participants with higher VEPOS remembered having more, not less, past positive mood. Yet, it seems that in our study this effect is due to the levels of positive cognitions (selfefficacy) of our participants. Regarding the analyses of the imagery modality, participants with higher vividness of kinesthetic imagery had higher levels of self-efficacy but not of optimism.

Our results replicate those of previous studies which found a relation between vividness of imagery of positive events and optimism (Blackwell et al., 2013; Ji et al., 2017; Sharot et al., 2007). However, our study adds the finding that this relationship extends to imagining different types of stimuli (i.e., positive situations involving actions rather than just positive situations). Moreover, we show that the imagery perspective matters in the relationship between vividness of imagery and optimism. Only the vividness of imagining actions in positive situations from an external but not from an internal perspective predicted optimism. We have further extended previous findings by showing that vividness of imagery for positive events is a possible cognitive marker for other types of resilience cognitions such as self-efficacy across both external and internal imagery perspectives and visual and kinesthetic imagery modalities.

People who imagine more vividly actions in positive situations have higher levels of optimism and self-efficacy

One way to explain the relationship between the level of vividness of imagining positive events and positive cognitions (optimism and self-efficacy) is by using the mental simulation framework (Hesslow, 2002; Ji et al., 2017; Kosslyn \& Moulton, 2009; Szpunar \& Schacter, 2013). According to this framework, people estimate the future by using perceptual simulations of future states (Kosslyn \& Moulton, 2009). When simulating positive future events, the simulation process triggers various metacognitive experiences such as ease of simulation, perceptual realness or emotional reactions (Ji et al., 2017; Tversky \& Kahneman, 1973; Mathews et al., 2013). When people see with their "mind eyes" more vividly how they are performing an action in a positive situation, because they will use vividness as information for estimating the likelihood of positive future, they will consider future positive events as more likely to occur. Similarly, information about the vividness of feelings of movement (i.e., kinesthetic images) when simulating actions may also be used for estimating the confidence of engaging in positive actions. This is in line with previous studies suggesting an availability heuristic as a foundation for selfefficacy (Cervone, 1989). Our results suggest a specificity of the effect of simulation heuristic on cognition depending on the processing style and the content of cognition. Thus, an external visual perspective may function as a marker for propositional types of positive cognitions while different types of markers may be used depending on the content of propositional cognition (vividness of visual-motor and kinesthetic imagery for action related cognition such as self-efficacy). Thus, although optimism may be based preferentially on visual simulations, the vividness of simulations of kinesthetic dimensions of positive experiences may additionally be used as a heuristic to estimate the ability for positive behaviors.

Previous studies showed that the memories of positive mood (estimations of the intensity of previous general feelings) are based on multiple sources of information such as current feelings (Bower, 1981), appraisals of the importance of events, and the memory of the intensity of their emotional reactions to past events (Kaplan et al., 2016). From a mental simulation framework (e.g., Tversky \& Kahneman, 1973) people may base their assessments of how positive they felt not only on remembering past emotions but also on the vividness of internal feelings and visual images at the very moment of estimating the level of past positive mood. People who imagine more vividly visual images and feelings of movements may use this metacognitive experience of vividness of visual images and feelings as information to make estimations of the intensity of past positive mood. Another possible explanation may be that imagining positive situations more vividly will also trigger online positive emotional reactions that will be used as a basis for estimating the intensity of previous feelings (Wyer et al., 1999). This interpretation is also in line with previous studies that showed that participants who recruit kinesthetic imagery have greater somatic arousal than participants who use external visual imagery (Davidson \& Schwartz, 1977). Our results suggest that the memory of positive mood is largely dependent on the level of propositional positive cognitions (self-efficacy) at the time of assessing past positive mood. As so, higher vividness of imagery results in remembering higher levels of positive mood because it prompts higher levels of positive cognition. Although it is possible that, in participants with lower levels of positive cognitions, the vividness of imagery will directly contribute to the memory of positive mood, in our sample this effect was explained by propositional cognitions.

The imagery perspective and the effect of vividness of imagery on positive cognitions

Our results indicate that vividness of imagining positive actions from an external visual perspective was linked not only with optimism but also with self-efficacy and memory of positive mood. We predicted that people with a high vividness of imagining positive events from an external visual perspective will have rather lower levels of 
self-report of past positive mood. Our results may seem contrary to previous studies which suggest that an external perspective is more likely linked to a blunted positive affect (Burnett-Heyes et al., 2017; Holmes et al., 2008) yet other studies using non-clinical samples did not find significant effects (Nelis et al., 2012).

One explanation of these differences comes from previous studies that show that the effect of perspective on emotions may be moderated by associated conceptual processing and self-concepts (Libby \& Eibach 2011a,b). For instance, Libby and her colleagues found that in people with positive goals, an external perspective was related to an increase in positive emotions such as enthusiasm (Libby et al., 2007). According to the processing style theory of visual perspective (Libby \& Eibach, 2011b), imagining events using an external visual perspective will prompt propositional processing. In people with high levels of selfrelated propositional positive cognitions (e.g., high selfesteem), using an external perspective when imagining positive events will prime positive cognitions and will result in endorsing higher levels of positive emotions. In our sample, participants had high levels of optimism and self-efficacy suggesting also a high level of positive selfview. Thus, our data comes to support this hypothesis. We found that VEPOS predicts higher levels of optimism and self-efficacy. Although VEPOS also predicts higher levels of the memory of positive mood, when controlling for the effects of self-efficacy, the relation between VEPOS and remembered positive mood has become non-significant. Thus, our results support the idea that higher vividness of external visual perspective prompts higher levels of conceptual processing, which, when positive, results in remembering higher levels of positive mood. This result is in line with findings about the effect of interventions focused on imagining self to target optimism: repeated imagery of what one does in a day at his best (best positive self) increases optimism (Meevissen et al., 2011; Peters et al., 2010) which in turn result in higher levels of positive emotions (Peters et al., 2010). These studies found that the relation between imagery and optimism is independent from positive affect (Meevissen et al., 2011; Peters et al., 2010). Studies that found that imagining positive events from an external perspective results in a blunted positive mood (e.g., Burnette Heyes et al., 2017; Holmes et al., 2008) used positive stimuli without reference to the self (e.g., imagine a positive image of a scene plus word). It may be that imagining positive items not including self from an observer perspective does not result in priming self-related positive processing by imagery (which most probably occurs for self-related items, Libby \& Eibach 2011a). Not increasing self-related processing may, in turn, deplete the effect of imagery on positive affect. Moreover, recent neuroscience findings further support this idea showing that the reductions in emotional intensity associated with an observer perspective are not automatic but result from appraising the situation in relation to the self-concept (precuneus activation, Grol et al., 2017).

Another explanation of the observed differences comes from differences between studies. While previous studies looked at the effect of manipulating the imagery perspective on experienced positive emotions (e.g., Burnett Heyes et al., 2017; Holmes et al., 2008), our study looked at trait differences in the relation between vividness of imagery and remembered positive mood. Thus, there may be a difference between the relation of trait vividness and past positive mood (i.e., as measured in our study and previous optimism-imagery vividness studies) and between vividness and ongoing positive mood (i.e., studies measured the effect of vividness of imagining positive events on subsequent positive emotions).

Our findings point to several important implications. Firstly, we showed that vividness of imagery is a potential mechanism for both optimism and self-efficacy. Accordingly, imagery-based interventions targeting vividness may act not only for increasing optimism but also self-efficacy (Short \& Ross-Stewart, 2008). Moreover, our result suggests that while only the external visual perspective predicts optimism, both the internal and the external perspectives of visual imagery and kinesthetic imagery may contribute to optimizing self-efficacy interventions.

Secondly, our findings suggest that the use of the external and not of the internal visual imagery perspective may optimize imagery interventions targeting optimism. Previous studies link imagery of positive situations from an external visual perspective to blunted affect and reactivity. These findings favor an internal perspective of imagery in interventions for promoting positive clinical outcomes. Combined with the abovementioned findings, our results lead to apparent contradictory recommendations about imagery perspective for imagery interventions for two important positive outcomes: while increasing optimism, imagining positive situations from an observer perspective may reduce positive mood. Although further research should clarify the effect of imagery perspective for selfrelated and self-independent items, we suggest that it may be two separate mechanisms that can be targeted in positive imagery interventions. In the same intervention, imagining a positive self-related situation from an observer perspective may enhance positive emotions through an increase in optimism and positive self-referential processing (i.e., "see yourself running while others applaud as they see you"), and through an internal perspective when imagining experiencing positive situations not related to self (i.e., "see that beautiful sunset as you see it through your eyes and let your body experience it"). Although this may be observed for people that have a positive selfconcept, for people with a negative self-concept, using an observer perspective may result in reduced positive affect and increased negative affect.

\section{Limitations}

Our results should be interpreted in the context of existing limitations. We have not manipulated the vividness of imagery. Thus, we cannot identify causal relationships between vividness and positive beliefs. In our study, participants had a fixed order of imagining each situation from the external, internal visual perspectives and kinesthetic modality which may have resulted in the observed differences between imagery conditions. Previous studies (Roberts et al., 2008) showed that this sequence yielded a valid measure of imagery perspective and visual and kinesthetic modalities. Both action items and task structure respected initial recommendations from VMIQ-R (Roberts et al., 2008). Yet, further studies may avoid possible order effects by randomising modality and alternating the order of imagining items. Another limitation is that using an internal after an external perspective may lead to the use of the external perspective in the internal condition as well. Post-hoc analyses of the actual use of imagery perspective during external and internal conditions suggest that participants used the perspective they were asked to use. Our sample represented an opportunistic sample selected through local advertising which may limit 
the generalisability of data. Furthermore, our sample had a high level of optimism which may hinder existing relations of optimism and impose constraints on interpreting the relations of optimism and other variables. Using samples with lower levels of optimism may clarify further the relationship between optimism and imagery.

\section{Further research}

This study has several suggestions for further research As suggested by present findings, computerized cognitive training interventions may use both types of perspectives when imagining positive situations: imagining self-related scenes from an observer perspective and a shift in the attentional focus on experience from an internal perspective. Further research may also clarify whether using an observer perspective in imagery is able to prompt positive self-related processing in people with former negative self-image but which underwent cognitive restructuring and have more positive self-concepts. This opens the possibilities of developing cognitive training interventions that strengthen cognitive restructuring.

Our study suggests that the external imagery perspective is at least as important as the internal imagery perspective for self-efficacy imagery interventions. Furthermore, we suggest that, rather than favoring one type of imagery perspective over the other, it is more relevant to take into account if individuals have a positive or negative self-image. Further research should clarify the relation between imagery perspectives and positive cognitions in clinical samples.

Also, our results suggest that whereas using visual imagery may suffice for interventions targeting optimism, interventions targeting self-efficacy may be improved by using also a kinesthetic modality. It is possible that increasing the vividness of feelings of movement might result in increased self-efficacy.

\section{Acknowledgements}

We especially thank Dafina Ionutiu for her thoughtful comments and efforts in drafting ideas of this article. We also thank Ana D'Amore for her continuous support of our work.

\section{References}

Bandura, A. (1997). Self-efficacy: The Exercise of Control. Freeman: New York, NY, USA,

Beauchamp, M.R., Bray, S.R., \& Albinson, J.G. (2002). Precompetition imagery, self-efficacy and performance in collegiate golfers. Journal of Sports Science, 20, 697-705.

Benight, C.C, \& Harper, M.L. (2002). Coping self-efficacy perceptions as a mediator between acute stress response and long-term distress following natural disasters. Journal of Traumatic Stress, 15, 177-186. pmid:12092909

Blackwell, S. E., Rius-Ottenheim, N., Schulte-van Maaren, Y. W. M., Carlier, I. V. E., Middelkoop, V. D., Zitman, F. G., ... Giltay, E. J. (2013). Optimism and mental imagery: A possible cognitive marker to promote well-being? Psychiatry Research, 206, 56-61. doi: 10.1016/j.psychres.2012.09.047

Bower, G. H. (1981). Mood and memory. American Psychologist, 36, 129 - 148.

Buck, D.J. M., Hutchinson, J. C., Winter, C. R. \& Thompson, B. A. (2016). The Effects of Mental Imagery with VideoModeling on Self-Efficacy and Maximal Front Squat Ability, Sports, 4, 23, doi:10.3390/sports 4020023
Burnett Heyes, S., Pictet, A., Mitchell, H., Raeder, S. M., Lau, J. Y. F., Holmes, E. A., \& Blackwell, S. E. (2017). Mental Imagery-Based Training to Modify Mood and Cognitive Bias in Adolescents: Effects of Valence and Perspective. Cognitive Therapy and Research, 41, 73-88. doi: 10.1007/s10608-016-9795-8

Carver, C.S., \& Scheier, M.F. (2014). Dispositional optimism. Trends in Cognitive Sciences, 18, 293-299. doi: 10.1016/j.tics.2014.02.003.

Cervone, D. (1989). Effects of envisioning future activities on self-efficacy judgments and motivation: An availability heuristic interpretation. Cognitive Therapy and Research 13, 247-261. doi: 10.1007/BF01173406

Davidson, R.J., \& Schwartz, G.E. (1977). Brain mechanisms subserving self-generated imagery: electrophysiological specificity and patterning. Psychophysiology, 14, 598-602.

Feng, J., Li S., \& Chen, H. (2015). Impacts of Stress, SelfEfficacy, and Optimism on Suicide Ideation among Rehabilitation Patients with Acute Pesticide Poisoning. PLoS ONE 10, e0118011. doi 10.1371/journal.pone.0118011

Folkman, S., Lazarus, R.S., Gruen R.J., \& DeLongis, A. (1986). Appraisal, coping, health status, and psychological symptoms. Journal of Personality and Social Psychology 50, 571-579.

Grangeon, M., Guillot, A., \& Collet, C. (2011). Postural control during visual and kinesthetic motor imagery. Applied Psychophysiology \& Biofeedback, 36, 47-56, doi: 10.1007/ s10484-011-9145-2

Grisham, J. R., Flower, K. N., Williams, A. D., \& Moulds, M. L. (2011). Reappraisal and rumination during recall of a sad memory. Cognitive Therapy Research, 35, 276-283, doi: 10.1007/s10608-009-9288-0

Grol, M., Vingerhoets G., \& De Raedt, R. (2017). Mental imagery of positive and neutral memories: A fMRI study comparing field perspective imagery to observer perspective imagery. Brain \& Cognition, 111, 13-24, doi: 10.1016/j.bandc.2016.09.014

Gruber, J., Harvey, A. G., \& Johnson, S. L. (2009). Reflective and ruminative processing of positive emotional memories in bipolar disorder and healthy controls. Behavior Research and Therapy, 47, 697-704, doi: 10.1016/j.brat.2009.05.005

Guillot, A., Collet, C., Nguyen, V. A., Malouin, F., Richards, C., \& Doyon, J. (2009). Brain activity during visual vs. kinesthetic imagery: An fMRI study. Human Brain Mapping, 30, 2157-2172. doi: 10.1002/hbm.20658

Hesslow, G. (2002). Conscious thought as simulation of behaviour and perception. Trends in Cognitive Sciences, 6 , 242-247 doi: 10.1016/S1364-6613(02)01913-7

Holmes, E.A, Coughtrey A.E, \& Connor, A. (2008). Looking at or through rose-tinted glasses? Imagery perspective and positive mood. Emotion 8, 875-879.

Hung, I. W., \& Mukhopadhyay, A. (2012). Lenses of the heart: how actors' and observers' perspectives influence emotional experiences. Journal of Counselling Research, $38,1103-1115$.

Jackson, P.L., Meltzoff, A.N., \& Decety, J. (2006). Neural circuits involved in imitation and perspective-taking. Neuroimage, 31, 429-439.

Jerusalem, M., \& Schwarzer, R. (2007). Scala de autoeficacitate [adaptat de Moldovan, R.]. in D. David (ed.), Sistem de evaluare clinică [Clinical Assessment System]. Ed. RTS, Cluj-Napoca

Ji, J. L., Holmes, E. A., \& Blackwell, S. E. (2017). Seeing light at the end of the tunnel: Positive prospective mental imagery and optimism in depression. Psychiatry Research, 247, 155-162. doi: 10.1016/j.psychres.2016.11.025

Kaplan, R. L., Levine, L. J., Lench, H. C., \& Safer, M. A. (2016). Forgetting feelings: Opposite biases in reports of 
the intensity of past emotion and mood. Emotion, 16, 309319. doi: $10.1037 / \mathrm{emo} 0000127$

Katzir, M., \& Eyal, T. (2013). When stepping outside the self is not enough: a self-distanced perspective reduces the experience of basic but not of self-conscious emotions. Journal of Experimental and Social Psychology, 49, 1089-1092. doi: 10.1016/j.jesp.2013.07.006

Kosslyn, S. M., \& Moulton, S. T. (2009). Imagining predictions: mental imagery as mental emulation. Philosophical Transactions of the Royal Society B, 364, 1273-1280.

Kroenke, K., Spitzer, R. L., \& Williams, J. B. W. (2001). The PHQ-9: Validity of a Brief Depression Severity Measure. Journal of General Internal Medicine, 16, 606-613. doi: 10.1046/j.1525-1497.2001.016009606.x

Kross, E., \& Ayduk, O. (2008). Facilitating adaptive emotional analysis: distinguishing distanced-analysis of depressive experiences from immersed-analysis and distraction. Personality and Social Psychological Bulletin, 34, 924938. doi: $10.1177 / 0146167208315938$

Libby, L. K., \& Eibach, R. P. (2011)a. Visual perspective in mental imagery: a representation tool that functions in judgment, emotion and self-insight. Advances in Experimental and Social Psychology, 44, 185-245, https://doi: 10.1016/B978-0-12-385522-0.00004-4

Libby, L. K., Shaeffer, E. M., Eibach, R. P., \& Slemmer, J. A. (2007). Picture yourself at the polls: Visual perspective in mental imagery affects self-perception and behavior. Psychological Science, 18, 199-203.

Libby, L. K., Valenti, G., Pfent, A., \& Eibach, R. P. (2011). Seeing failure in your life: imagery perspective determines whether self-esteem shapes reactions to recalled and imagined failure. Journal of Personality and Social Psychology, 101, 1157-1173, doi: 10.1037/a0026105

Libby, L.K., \& Eibach, R.P. (2011)b. Visual perspective in mental imagery: A representational tool that functions in judgment, emotion, and self-insight. In M.P. Zanna and J.M. Olson (Eds.), Advances in Experimental Social Psychology (Vol. 44, pp. 185 - 245). San Diego: Academic Press.

Libby, L.K., Valenti, G., Hines, K., \& Eibach, R.P. (2014). Using imagery perspective to access two distinct forms of self-knowledge: Associative evaluations versus propositional self-beliefs. Journal of Experimental Psychology: General, 143, 492 - 497.

MacLeod, A.K., Byrne, A., \& Valentine, J.D. (1996). Affect, emotional disorder, and future directed thinking. Cognition and Emotion, 10, 69-86.

Magaletta, P.R., \& Oliver, J. (1999). The hope construct, will, and ways: Their relations with self $\square$ efficacy, optimism, and general well-being. Journal of Clinical Psychology, $55,539-551$.

Malouff, J.M., \& Schutte, N.S.(2016). Can psychological interventions increase optimism? A meta-analysis. Journal of Positive Psychology, 12, 594-604. doi: 10.1080/17439760.2016.1221122

Mathews, A., Ridgeway V., \& Holmes E. A. (2013). Feels like the real thing: Imagery is both more realistic and emotional than verbal thought. Cognition and Emotion, 27, 217-229, doi: 10.1080/02699931.2012.698252

Meevissen, Y.M.C., Peters, M.L., Alberts, H.J.E.M., 2011. Become more optimistic by imagining a best possible self: effects of a two week intervention. Journal of Behavior Therapy and Experimental Psychiatry 42, 371-378.

Morina, N., Deeprose, C., Pusowski, C., Schmid, M., \& Holmes E.A. (2011). Prospective mental imagery in patients with major depressive disorder or anxiety disorders. Journal of Anxiety Disorders, 25, 1032-1037.

Nelis, S., Debeer, E., Holmes, E. A., \& Raes, F. (2013). Dysphoric students show higher use of the observer perspective in their retrieval of positive versus negative autobiographical memories. Memory, 21, 423-430. doi: 10.1080/09658211.2012.730530

Nelis, S., Vanbrabant, K., Holmes, E. A., \& Raes, F. (2012). Greater positive affect change after mental imagery than verbal thinking in a student sample. Journal of Experimental Psychopathology, 3, 178-188. doi: $10.5127 /$ jep. 021111

Nigro, G., \& Neisser, U. (1983). Point of view in personal memories. Cognitive Psychology, 15, 467-482.

Opris, D. \& Macavei, M. (2007). Profilul distresului afectiv [The Profile of Affective Distress]. in D. David (ed.), Sistem de evaluare clinică [Clinical Assessment System]. Ed. RTS, Cluj-Napoca

Peters, L. M., Flink, I. K., Boersma, K., \& Linton, S. J. (2010). Manipulating optimism: can imagining a best possible self be used to increase positive future expectancies? The Journal of Positive Psychology, 5, 204-211. doi: 10.1080/17439761003790963.

Rasmussen, H.N., Scheier, M.F., \& Greenhouse, J.B. (2009) Optimism and physical health: A meta-analytic review. Annals of Behavioral Medicine, 37, 239-256, doi: 10.1007/s12160-009-9111-x.

Roberts, R., Callow, N., Hardy, L., Markland, D., \& Bringer, J. (2008). Movement imagery ability: Development and assessment of a revised version of the Vividness of Movement Imagery Questionnaire. Journal of Sport \& Exercise Psychology, 30, 200-221.

Scheier, M. F., Carver, C. S., \& Bridges, M. W. (1994). Distinguishing optimism from neuroticism (and trait anxiety, self-mastery, and self-esteem): A re-evaluation of the Life Orientation Test. Journal of Personality and Social Psychology, 67, 1063-1078.

Schwarzer, R., \& Jerusalem, M. (1995). Generalized SelfEfficacy scale. In J. Weinman, S. Wright, \& M. Johnston, Measures in health psychology: A user's portfolio. Causal and control beliefs (pp. 35- 37). Windsor, England: NFER-NELSON

Shaeffer, E.M., Eibach, R.P., \& Libby, L.K. (2015). Changing visual perspective changes processing style: A distinct pathway by which imagery guides cognition. Journal of Experimental Psychology: General, 144, 534 - 538.

Sharot, T., Riccardi, A.M., Raio, C.M., \& Phelps, E.A. (2007). Neural mechanisms mediating optimism bias. Nature, 450, 102-105.

Short, S.E., \& Ross-Stewart, L. (2008). A review of selfefficacy based interventions. In S. Mellalieu \& S. Hanton (Eds.) Applied Sport Psychology Advances: A Review. London, UK: Routledge.

Sirigu, A., \& Duhamel, J. R. (2001). Motor and visual imagery as two complementary but neutrally dissociable mental processes. Journal of Cognitive Neuroscience, 13, 910919, doi: 10.1162/089892901753165827

Stinear, C. M., Byblow, W. D., Steyvers, M., Levin, O., \& Swinnen, S. P. (2006). Kinesthetic, but not visual, motor imagery modulates corticomotor excitability. Experimental Brain Research, 168, 157-164, doi:10.1007/s00221-005-0078-y

Stins, J. F., Schneider, I. K., Koole, S. L., \& Beek, P. J. (2015). The influence of motor imagery on postural sway: Differential effects of type of body movement and person perspective. Advances in Cognitive Psychology, 11, 7783. doi:10.5709/acp-0173-x

Stober, J. (2000). Prospective cognitions in anxiety and depression: replication and methodological extension. Cognition \& Emotion, 14, 725-729.

Szpunar, K. K., \& Schacter, D. L. (2013). Get real: Effects of repeated simulation and emotion on the perceived plausibility of future experiences. Journal of Experimental Psychology. General, 142, 323-327. doi: $10.1037 / \mathrm{a} 0028877$ 
Tversky, A., \& Kahneman, D. (1973). Availability: A heuristic for judging frequency and probability. Cognitive Psychology, 5, 207-232.

Wallace-Hadrill, S. M. A., \& Kamboj, S. K. (2016). The Impact of Perspective Change As a Cognitive Reappraisal Strategy on Affect: A Systematic Review. Frontiers in Psychology, 7, 1715. doi: 10.3389/fpsyg.2016.01715

White, R. E., Kross, E., \& Duckworth, A. L. (2015). Spontaneous Self-Distancing and Adaptive Self-Reflection Across Adolescence. Child Development, 86, 1272-1281. doi: 10.1111/cdev.12370

Williams, A. D., \& Moulds, M. L. (2008). Manipulating recall vantage perspective of intrusive memories in dysphoria Memory, 16, 742-750. doi:10.1080/09658210802290453
Wisco, B. E., \& Nolen-Hoeksema, S. (2011). Effect of visual perspective on memory and interpretation in dysphoria. Behaviour Research and Therapy, 49, 406-412. doi: 10.1016/j.brat.2011.03.012

Wyer, R. S., Clore, and G. L., and Isbell, L. (1999). Affect and information processing. M. Zanna (Ed.), Advances in Experimental Social Psychology (Vol. 31, pp. 1-77). New York: Academic Press.

World Medical Association (2013). WMA declaration of Helsinki: Ethical principles for medical research involving human subjects. Retrieved from:

http://www.wma.net/en/30publications/10policies/b3/ 